\title{
Treatment of Birch Xylan with Chlorine in Aqueous Solution
}

\author{
THOMAS ERICSSON and OLOF SAMUELSON
}

Department of Engineering Chemistry, Chalmers University of Technology, S-402 20 Göteborg, Sweden

The depolymerization of xylan by chlorine in aqueous solution resulted in the formation of xylonic acid and reducing xylose end groups. Glyceric, threonic and 2-O-(4-O-methyl- $\alpha-\mathrm{D}$ glucopyranosyluronic acid)-D-xylonic acid moieties were present in minor amounts. Some of the reducing galacturonic acid moieties glycosidically linked to potentially reducing xylose end groups were split off during the chlorine treatment.

Chlorination is an important stage in the production of bleached wood pulps. Kinetic studies and a review of older publications were presented by Fredricks, Lindgren and Theander. ${ }^{1}$ The formation of acid groups in the cellulose was studied recently ${ }^{2}$ but no studies seem to have been published on the reactions of hemicellulose. To fill this gap we now report on reactions which occur when xylan is treated with chlorine in aqueous solution.

\section{EXPERIMENTAL}

The xylan sample was the same as that used in a study of the galacturonic acid end groups in birch xylan. ${ }^{3}$ The sample $(34.8 \mathrm{~g})$ was treated with $725 \mathrm{ml}$ of an aqueous solution containing $5.12 \mathrm{~g} \mathrm{Cl}_{2} / 1$ for $8 \mathrm{~h}$ at $27.7^{\circ} \mathrm{C}$. During the entire treatment, which was carried out in darkness, $3.7 \mathrm{~g} \mathrm{Cl}_{2}$ were consumed. The $\mathrm{pH}$ decreased from 1.8 to 1.5. The excess chlorine was destroyed with sulfurous acid and ethanol was added to precipitate the xylan. After centrifugation the precipitate was washed first with $50 \%$ ethanol and then with water on an ultrafilter [Amicon UM-2]. Finally, the xylan was washed successively with $70 \%$ ethanol, absolute ethanol and ethyl ether and dried under vacuum. The loss in yield during the treatment was $23 \%$.

The xylan sample was hydrolyzed and after removal of hydrochloric acid the organic material was separated into a non-electrolyte frac- tion, a fraction containing non-volatile monocarboxylic acids and a dicarboxylic acid fraction."

The carbonyl end groups in the xylan samples were determined after reduction to alditols by potassium borohydride. ${ }^{5}$ The xylan sample $\mathbf{7 . 5}$ g) was stirred in $350 \mathrm{ml} 0.01 \mathrm{M}$ sodium hydroxide, containing $25 \mathrm{~g}$ sodium chloride per litre, for $24 \mathrm{~h}$ under nitrogen to split lactones. After neutralization with hydrochloric acid 3.9 $\mathrm{g}$ of potassium borohydride were added. The suspension was stirred for $75 \mathrm{~h}$. The xylan was precipitated with acetic acid and ethanol and after centrifugation the sample was washed with ethanol and ether and dried. In the experiment with the untreated xylan the loss in yield was $6.8 \%$ whereas with the chlorinated sample the corresponding value was $14.3 \%$. The reduced sample was hydrolyzed and the hydrolyzate was separated into three fractions."

The non-volatile acids present in the monocarboxylic acid fraction were separated by anion exchange chromatography in $0.08 \mathrm{M}$ sodium acetate. ${ }^{6}$ The composition of the eluate was recorded with a Waters' R4 differential refractometer. The acids present in the individual fractions were tentatively identified by anion exchange chromatography in sodium acetate and acetic acid media using an automatic three-channel analyzer." When several acids were present the fractions were rechromatographed on a preparative scale with 1.0 or 0.5 $M$ acetic acid, $0.02 \mathrm{M}$ sodium acetate and 0.15 M sodium tetraborate as eluents.

The aldonic (including glycolic) acids as well as 2,4-dihydroxybutanoic ${ }^{8}$ and galacturonic acids were identified by combined gas chromatography-mass spectrometry. The other uronic acids were identified by their $D_{\mathrm{v}}$ values, color reactions and hydrolysis products. 3,4Dihydroxybutanoic acid was identified by its $D_{\mathrm{v}}$ values and by gas chromatography whereas the deoxypentonic acids which were present in trace amounts were identified by gas chromatography only.

All weights of the individual acids are reported per $100 \mathrm{~g}$ xylan. Most figures were obtained by weighing the isolated acids. With species present in very small amounts estimates were made 
Table 1. Relative carbohydrate composition, $\%$ by weight.

\begin{tabular}{lclll}
\hline & $\begin{array}{l}\text { Untreated } \\
\text { xylan }\end{array}$ & $\begin{array}{l}\text { Chlorinated } \\
\text { xylan }\end{array}$ & $\begin{array}{l}\text { Chlorinated } \\
\text { reduced } \\
\text { xylan }\end{array}$ & $\begin{array}{l}\text { Solution } \\
\text { after } \\
\text { chlorination }\end{array}$ \\
\hline Rhamnose & 1.52 & 1.19 & 0.46 & 3.73 \\
threo-2-Pentulose & 0.18 & 0.34 & 0.14 & 0.41 \\
Lyxose & 0.04 & 0.02 & 0.06 & 0.07 \\
Arabinose & 0.04 & trace & trace & 0.42 \\
Xylose & 97.1 & 98.1 & 99.3 & $\mathbf{8 9 . 5}$ \\
Mannose & 0.47 & 0.13 & trace & 1.93 \\
Galactose & 0.30 & trace & trace & 2.21 \\
Glucose & 0.29 & 0.20 & trace & 1.00 \\
\hline
\end{tabular}

from the areas recorded on the chromatograms.

The sugars and alditols were determined by partition chromatography in aqueous ethanol on both an anion exchanger in the sulfate form and a cation exchanger in the lithium form.

\section{RESULTS AND DISCUSSION}

A study of the carbohydrate composition of the isolated xylan showed that minor amounts of polysaccharides containing rhamnose, mannose, galactose, and glucose and trace amounts of arabinose were present (Table 1). Their contents decreased during treatment with chlorine and these constituents were enriched in the non-electrolyte fraction, isolated from the solution after removal of the soluble acids by means of an anion exchanger. This fraction which contained mainly oligomeric sugars was obtained in a yield of $4.6 \%$ calculated on the xylan.

The number of xylitol end groups in the xylan after reduction with potassium boro-

Table 2. End groups in reduced xylan, $\mathrm{mmol}$ per $100 \mathrm{~g}$.

\begin{tabular}{lll}
\hline & $\begin{array}{l}\text { Before } \\
\text { chlorination }\end{array}$ & $\begin{array}{l}\text { After } \\
\text { chlorination }\end{array}$ \\
\hline Xylitol & 0.82 & 2.12 \\
Lyxitol & 0.136 & 0.08 \\
Threitol & 0.103 & - \\
Erythritol & 0.026 & - \\
Xylonic acid & 0.121 & 4.69 \\
Lyxonic acid & 0.87 & 0.32 \\
Threonic acid & 0.50 & 0.38 \\
Glyceric acid & 0.83 & 1.13 \\
Galactonic acid & 2.68 & 1.09 \\
Total amount & 6.09 & $\mathbf{9 . 8 1}$ \\
\hline
\end{tabular}

hydride was $0.82 \mathrm{mmol}$ per $100 \mathrm{~g}$ whereas after chlorination it was 2.12 (Table 2). Evidently, the number of reducing xylose end groups increased markedly during the treatment but still remained low compared to that expected from the DP of the xylan. These observations which at first seemed puzzling are explained by the finding that in the untreated xylan a large portion of the potentially reducing xylose end groups were, at C-1, linked glycosidically to a reducing terminal galacturonic acid moiety. The amount of galacturonic acid in the hy. drolyzate from the untreated xylan was significantly higher than that obtained after chlorine treatment (Table 3), demonstrating that galact. uronic acid groups are in part split off during this treatment. As previously shown the reducing galacturonic acid end groups which constitute only a fraction of the total number of the terminal galacturonic acid moieties are reduced to galactonic acid end groups by borohydride. While galacturonic acid suffers severe degradation during acid hydrolysis, galactonic acid can be recovered almost quantitatively. ${ }^{10}$ If the loss in galacturonic acid groups is due to a loss of terminal reducing galacturonic acid moieties, the amount of galactonic acid end groups in the reduced sample should be much less after treatment with chlorine. The results given in Table 2 show that the number of galactonic acid end groups in the reduced starting material was $2.68 \mathrm{mmol}$ per $100 \mathrm{~g}$ whereas in the chlorinated (and subsequently reduced) xylan it was 1.09. A large portion of reducing galacturonic acid end groups disappeared during the chlorination but an appreciable amount remained.

Acta Chem. Scand. B 29 (1975) No. 3 
Table 3. Monocarboxylic acids isolated from the hydrolyzates of xylan. The weights refer to $100 \mathrm{~g}$ xylan.

\begin{tabular}{|c|c|c|c|c|}
\hline Acids & $\begin{array}{l}\text { Untreated } \\
\text { xylan } \\
\text { mg }\end{array}$ & $\begin{array}{l}\text { Untreated } \\
\text { reduced } \\
\text { xylan } \\
\text { mg }\end{array}$ & $\begin{array}{l}\text { Chlorinated } \\
\text { xylan } \\
\text { mg }\end{array}$ & $\begin{array}{l}\text { Chlorinated } \\
\text { reduced } \\
\text { xylan } \\
\text { mg }\end{array}$ \\
\hline \multirow{4}{*}{ 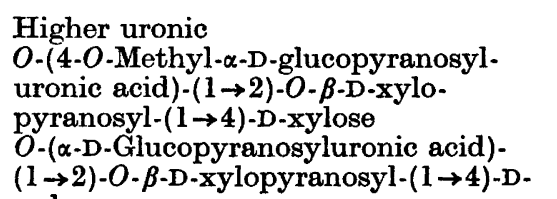 } & - & 62 & 58 & 130 \\
\hline & & & & \\
\hline & 340 & 166 & 322 & 198 \\
\hline & & & & \\
\hline xylose & 140 & 100 & 68 & 94 \\
\hline Unknown uronic ( $\left.D_{\mathrm{v}} 5.6,0.5 \mathrm{M} \mathrm{HAc}\right)$ & - & - & 14 & 60 \\
\hline \multirow{5}{*}{$\begin{array}{l}\text { 2-O-(4-O-Methyl- } \alpha \text {-D-glucopyranosyl- } \\
\text { uronic acid)-D-xylose } \\
\text { 2-O-(4-O-Methyl- } \alpha \text {-D-glucopyranosyl- } \\
\text { uronic acid)-D-xylitol }\end{array}$} & 160 & 140 & 216 & 182 \\
\hline & & & & \\
\hline & 5886 & 5344 & 6336 & 6064 \\
\hline & - & 2 & - & 22 \\
\hline & & & & \\
\hline acid)-D-xylose & 410 & 140 & 654 & 274 \\
\hline 4-O-Methylglucuronic & 1502 & 1322 & 2000 & 1316 \\
\hline Glucuronic & 24 & 16 & 40 & 10 \\
\hline \multicolumn{5}{|l|}{$\begin{array}{l}\text { Dianhydrides of } 2-O-(4-O \cdot \text { Methyl- } \\
\alpha \cdot D \text {-glucopyranosyluronic acid })-\mathrm{D} \text {. }\end{array}$} \\
\hline xylose $\left(D_{\mathrm{v}}=26 ; 0.5 \mathrm{M} \mathrm{HAc}\right)$ & 188 & 246 & 188 & 168 \\
\hline$\left(D_{\mathrm{v}}=45 ; 0.5 \mathrm{M} \mathrm{HAc}\right)$ & 220 & 144 & 262 & 212 \\
\hline \multirow{2}{*}{\multicolumn{5}{|c|}{ 2.O-( $\alpha$-D-Galatopyranosyluronic }} \\
\hline & & & & \\
\hline acid)-L-rhamnose & 30 & 18 & 30 & trace \\
\hline Galacturonic & 628 & 248 & 522 & 16 \\
\hline Galactonic & - & 526 & - & 214 \\
\hline Xylonic & 38 & 20 & 1590 & 778 \\
\hline 3-Hydroxypropionic & 24 & trace & trace & 78 \\
\hline Lyxonic & 106 & 144 & $\mathbf{5 4}$ & 53 \\
\hline Threonic & 40 & 68 & 112 & 51 \\
\hline Glyceric & 92 & 88 & 186 & 120 \\
\hline Glycolic & - & & trace & 36 \\
\hline 2-Deoxytetronic & 4 & 12 & trace & 8 \\
\hline 3-Deoxytetronic & - & & 62 & trace \\
\hline 2-Deoxy-threo-pentonic & - & 1 & trace & - \\
\hline 3-Deoxy-erythro-pentonic & - & 4 & trace & - \\
\hline
\end{tabular}

The number of lyxitol end groups in the reduced xylan samples decreased during treatment with chlorine (Table 2). These groups are derived from terminal lyxose and threo-2-pentulose moieties formed by Lobry de BruynAlberda van Ekenstein transformations of xylose end groups in the alkaline solution used for the isolation of the xylan. In addition to xylitol and lyxitol end groups, small amounts of threitol and erythritol end groups were observed in the starting material (after reduction). Only traces were recorded in the chlo. rinated and reduced xylan. The results permit the conclusion that small amounts of threose and erythrose end groups were present in the original hemicellulose but disappeared during the chlorine treatment. Oxidation of terminal reducing units gives rise to the corresponding aldonic acid end groups but as shown below these terminal groups can be further attacked.

Among the aldonic acids which are derived from the end groups, lyxonic acid was present in larger amounts before the treatment with chlorine. Lyxonic acid end groups are formed by oxidation of xylan by oxygen in alkaline medium ${ }^{11}$ and their presence can be ascribed

Acta Chem. Scand. B 29 (1975) No. 3 
Table 4. Viscosity of the xylan samples in copper ethylenediamine solution.

$\begin{array}{llll}\text { Untreated } & \begin{array}{l}\text { Untreated } \\ \text { xylan }\end{array} & \begin{array}{l}\text { Chlorinated } \\ \text { xylan }\end{array} & \begin{array}{l}\text { Chlorinated } \\ \text { xylan } \\ \text { xylan }\end{array} \\ & \text { xylan }\end{array}$

\section{Viscosity}

$[\eta], \mathrm{cm}^{\mathbf{3}} / \mathrm{g}$

DP, calculated 12

from $[\eta]$
100

212
98

208
56

119
62 to a partial oxidation of xylose end groups during the procedure used for the isolation of the xylan.

As can be seen from Table 3 very large amounts of xylonic acid end groups were formed during the chlorine treatment. This reaction was expected since the formation of terminal gluconic acid moieties is one of the more important cellulose reactions during the treatment with chlorine.2 No mannonic acid was formed in the cellulose and analogously no formation of lyxonic acid was observed in the experiments with xylan. The decrease in lyxonic acid content can be ascribed to a degradation to threonic and glyceric acid end groups ( $c f$. Appendix I) and to the loss of low molecular weight xylan.

The number of xylonic acid groups was much lower in the sample reduced with potassium borohydride. The chlorinated xylan was kept in alkaline solution to split lactones and other possible ester linkages before addition of borohydride. This means that no reduction of the xylonic acid end groups should occur. The decrease is probably due to an appreciable amount $(14.3 \%)$ of the xylan being lost and the dissolved fraction having a low molecular weight (cf. Table 4).

Similarly, the amounts of threonic and glyceric acids in the chlorine treated sample were much higher before the reduction. The results given in the table permit the conclusion that threonic and glyceric acid end groups were formed during the treatment with chlorine. Their presence before the chlorine treatment is in accordance with the observation that not only lyxonic acid but also threonic and glyceric acids are formed as end groups during the isolation of xylan.
The determination of terminal moieties consisting of aldonic acids or alditols in the reduced xylan samples are listed in Table 2 . If it is assumed that these and only these end groups are present in the potentially reducing end, the total amounts would be $6.09 \mathrm{mmol} / 100 \mathrm{~g}$ before and $9.81 \mathrm{mmol} / 100 \mathrm{~g}$ after the treatment with chlorine. The values correspond to a (DP) $)_{n}$ of 109 and 68, respectively. In these calculations it was assumed that every tenth xylose unit contained a 4-O-methylglucuronic acid moiety. A calculation of the DP from the viscosity ${ }^{12}$ gave the values 208 and 131 .

Two diastereomeric 3-deoxypentonic acids (which cannot be present as end groups) were found in the hydrolyzate of cellulose.2 When the chlorinated sample was treated with potassium borohydride before the hydrolysis these acids were absent. These results together with the observation that 3-deoxytetronic acid was present in the hydrolyzate from chlorinated xylan but was not detected when the sample was reduced (see Table 3), strongly indicate that these 3-deoxyaldonic acids are derived from oxidized units in the polysaccharide chains, or more specifically from sugar moieties containing a keto group. Most likely the keto groups are present at $\mathrm{C}-2$, i.e. the oxidized moieties are hexosulose in cellulose and pentos. ulose in xylan.

A small amount of glyoxylic acid was found in similar experiments with cellulose. ${ }^{2}$ It was concluded that the bond between carbon atoms 2 and 3 in a non-terminal glucose moiety was broken and carboxylic acid groups were formed in these positions. After treatment of birch xylan with chlorine no glyoxylic acid was found. One explanation would be that the chlorine treatment of the birch xylan was carried out 
Table 5. Volume distribution coefficients $\left(D_{\mathrm{v}}\right)$ of 2-O-(4-O-methyl- $\alpha$-D-glucopyranosyluronic acid)D-xylonic acid in ion exchange chromatography on Dowex 1-X8.

\begin{tabular}{|c|c|c|}
\hline Medium & ${ }^{\circ} \mathrm{C}$ & $D_{\mathrm{v}}$ \\
\hline $\begin{array}{l}0.3 \mathrm{M} \text { Sodium acetate, } 2 \mathrm{M} \text { acetic acid } \\
5.0 \mathrm{M} \text { Acetic acid } \\
0.2 \mathrm{M} \text { Magnesium acetate, } \mathrm{pH} 7.0 \\
0.3 \mathrm{M} \text { Magnesium acetate, } \mathrm{pH} 7.0\end{array}$ & $\begin{array}{l}30 \\
30 \\
70 \\
70\end{array}$ & $\begin{aligned} & 4.8(12.5) \\
& 22.2(19.0) \\
& 6.7(10.5) \\
& 3.0(4.1)\end{aligned}$ \\
\hline
\end{tabular}

The $D_{\mathrm{v}}$ values given within parenthesis refer to galactaric acid.

Table 6. Oxidation of model compounds.

\begin{tabular}{|c|c|c|c|c|c|c|}
\hline \multirow[t]{2}{*}{ Added acid } & \multirow[t]{2}{*}{ mg } & \multicolumn{3}{|c|}{ Amounts of acids after chlorination, $\mathrm{mg}$} & \multirow[b]{2}{*}{ Glycolic } & \multirow[b]{2}{*}{ Carbonic } \\
\hline & & Xylonic & Threonic & Glyceric & & \\
\hline Xylonic & 25.6 & 15.4 & 5.6 & 1.1 & 1.1 & n.d. ${ }^{a}$ \\
\hline Threonic & 33.2 & - & 25.6 & 3.6 & 2.1 & n.d. \\
\hline Glyceric & 196.5 & - & - & 68.6 & 80.1 & $\mathbf{5 8 . 5}$ \\
\hline Glycolic & 182.9 & - & - & - & 171.6 & 7.7 \\
\hline
\end{tabular}

$a_{\text {n.d. }}=$ not determined

at a lower $\mathrm{pH}(1.8)$ than that (2.5) used in the experiments with cellulose (cf. Ref. 13).

The uronic acids present in the hydrolyzates before chlorine treatment were the same as found in previous investigations. ${ }^{14}$ The amount of the predominant 4-O-methylglucuronic acid and of the corresponding biouronic and higher uronic acids must, considering the errors involved in the hydrolysis procedure, be considered to be about the same as after the treatment with chlorine.

An interesting observation is that the dicarboxylic acid fraction contained an appreciable amount $(0.331 \mathrm{mmol}$ per $100 \mathrm{~g}$ xylan) of 2-O-(4-O-methyl- $\alpha$-D-glucopyranosyluronic acid)-D-xylonic acid. This acid has not been studied previously and the volume distribution coefficients $\left(D_{\mathrm{v}}\right)$ found on ion exchange chromatography are given in Table 5. The retention of the trimethylsilyl derivative (ester) relative to that of cellobiitol on OV-1 at $250^{\circ} \mathrm{C}$ was 0.614 ( $c f$. Ref. 8). The identity was established by comparison with the data obtained with a sample prepared by hypochlorite oxidation of 2-O-(4-O-methyl- $\alpha$-D-glucopyranosyluronic acid)-D-xylose. The presence of this acid shows that terminal xylose units containing a 4-O-methylglucuronic acid substituent are oxidized to the corresponding xylonic acid moiety. No appreciable amounts of other dicarboxylic acids were present.

Appendix I. Oxidation of glycolic, glyceric, threonic, and xylonic acids with chlorine.

Glycolic, glyceric, threonic, and xylonic acids were in separate experiments treated for $48 \mathrm{~h}$ at $28{ }^{\circ} \mathrm{C}$ with $200 \mathrm{~cm}^{3}$ of an aqueous solution containing $5.7 \mathrm{~g} \mathrm{Cl}_{2}$ per litre. The excess chlorine was destroyed with sulfurous acid and the solutions kept at $\mathrm{pH} 8.5$ for $4 \mathrm{~h}$ at room temperature. The monocarboxylic acid fraction was isolated and analyzed. Dicarboxylic acids and sugars were not present in appreciable amounts. The results given in Table 6 show that glycolic acid was very stable. Only about $4 \%$ were converted into carbon dioxide. Glyceric acid was severely attacked. The glycolic and carbonic acids produced account for $95 \%$ of the loss. Threonic acid gave rise to glyceric and glycolic acids but the decomposition was less severe than that of glyceric and xylonic acids. Threonic, glyceric, and glycolic acids were produced from xylonic acid.

It is worth mentioning that the conditions used in the model experiments were more severe than those used in the experiments with xylan. However, the results lend support to 
the conclusion that the aldonic acid end groups in xylan are oxidized during treatment of xylan with chlorine and converted into terminal moieties consisting of lower aldonic acids.

Acknowledgements. The authors wish to thank the 1959 Arr Fond för Teknisk och Skoglig Forskning samt Utbildning for financial support. Thanks are also due to Dr. Göran Petersson who carried out the mass spectrometric investigations.

\section{REFERENCES}

1. Fredricks, P., Lindgren, B. and Theander, O. Svensk Papperstidn. 74 (1971) 597.

2. Alfredsson, B. and Samuelson, O. Svensk Papperstidn. 77 (1974) 449.

3. Ericsson, T., Petersson, G. and Samuelson, O. To be published.

4. Kolmodin, H. and Samuelson, O. Svensk Papperstidn. 75 (1972) 369.

5. Päärt, E. and Samuelson, O. Carbohyd. Res. $15(1970) 111$.

6. Samuelson, O. and Stolpe, L. Tappi 52 (1969) 1709.

7. Carlsson, B., Isaksson, T. and Samuelson, O. Anal. Chim. Acta 43 (1968) 47.

8. Petersson, G. Tetrahedron 26 (1970) 3413.

9. Samuelson, $\mathrm{O}$. and Strömberg, H. Acta Chem. Scand. 22 (1968) 1252.

10. Norstedt, I. and Samuelson, O. Svensk Papperstidn. 69 (1966) 729.

11. Kolmodin, H. and Samuelson, O. Svensk Papperstidn. 76 (1973) 71.

12. Glaudemans, C. P. J. and Timell, T. E. Svensk Papperstidn. 61 (1958) 1.

13. Whistler, R. L. and Schweiger, R. J. Amer. Chem. Soc. 79 (1957) 6460.

14. Shimizu, K. and Samuelson, O. Svensk Papperstidn. 76 (1973) 150.

Received September 26, 1974. 